\title{
La biblioteca y el laberinto
}

\author{
HÉCTOR Guillermo AlFaro Ló Pez \\ Centro Universitario de Investigaciones Bibliotecológicasde \\ la UNAM, 04510, México D.F., Tel: 56-23-03-29 \\ E-mail:galfaro@ cuib.unam.mx
}

Para Patricia Hemández Salazar
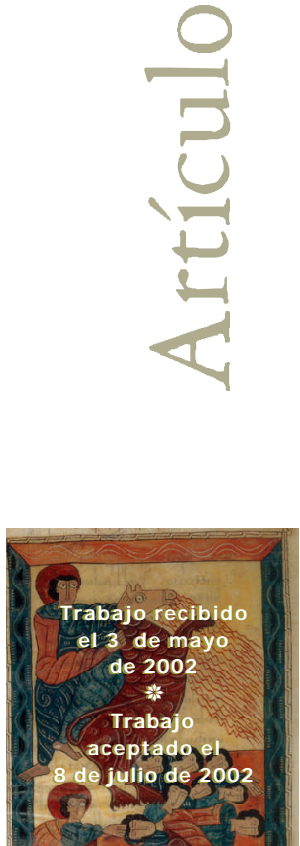

\section{RESUMEN}

La novela El nombredelarosaproporciona información sobre las características específicas de la biblioteca medieval, lo que permite investigar como ésta en gran medida era consecuencia y obediencia al contexto histórico social de ese momento. Entre esas características se destacan sus mecanismos de censura y el papel que en ello jugaba el bibliotecario. Asimismo se explica cómo en ese modelo de biblioteca se llevaba a cabo una prototípica interacción sobre las prácticas de la lectura y la escritura de la Edad Media.

Palabras clave: Censura, lectura y escritura, Edad Media, biblioteca.

\section{THE LIBRARY AND THE LABYRINTH \\ HÉCTOR GUILLERMO ALFARO-LÓPEZ}

\section{ABSTRACT}

The novel El nombredela rosa affords us with information about the specific characteristics of the medieval library and allows us to investigate how this was in great measure consequence of and an obedience to the historical and social context of the time. The review shows the mechanisms for censorship and the role the librarian himself played in this. Also explained is the way in which that library model carried a prototypical interaction in the practices of reading and writing in the Middle Ages.

Keywords: Censorship, Reading and Writing, Middle Ages, Library. 
U monje bibliotecario ciego huye entre las salas heptagonales de una biblioteca aberinto acosado por un monje detective y su discípulo. En su huida el biblioecario va poseído por el demonio de la bibliofagia, desgarra las páginas de un manuscrito para meterse sus despojos en la boca y los va masticando con creciente voracidad. Las páginas del manuscrito están envenenadas. D e la desdentada boca mana una saliva amarilla y las facciones de su anciano rostro se desfiguran en una mueca de maldad. La blancura sin luz de sus ojos se tiñe de sangre, de la atragantada boca escapan jirones del pergamino como no resignándose a ese fin. El doble veneno, el de la sustancia química y el del contenido del manuscrito, recorre su cuerpo ya consumiéndolo. Las páginas de la segunda parte de la Pớica de A ristóteles van matando al bibliotecario. Cada página que devora del manuscrito es un vacío que se abre en la cultura occidental, pero él considera que así preserva la inmovilidad sagrada de ese orden cultural, pues al ser el único ejemplar que existe de tal obra su corrosivo peligro desaparecerá para siempre. El veneno intelectual que para este monje que huye destila el inversamente famoso texto aristotélico es la risa, a diferencia de su primera parte cuyo tema es la tragedia, propiciadora del llanto. Al sentirse orgulloso producto y, por lo mismo, insobornable vigilante del orden medieval establecido, el monje ciego se considera un predestinado para acabar con todo aquello que atente contra lo que él representa y preserva. Se trata de un pétreo orden jerárquico cuya columna central es la institución eclesiástica, sobre la cual descansa la pesada bóveda de una estructura social que no admite cambios y menos aún innovaciones. Es un orden concebido para durar, no para cambiar. Pero el monje bibliotecario sabe muy bien que existen peligros más sutiles y "aparentemente" más inocentes contra los que debe estar atento, porque en el fondo son los mayormente disolventes del orden. Y de ellos un enemigo principal del status medieval, en este caso ya en plena decadencia, es la risa. Una institución oficial que sólo concibe este mundo terrenal como un pesaroso tránsito hacia la redención acaba pornecesidad temiendo a la risa: el camino del sufrimiento que se tiene que recorrer en este mundo debe ser asumido con toda la seriedad trágica posible. Reflejo y ejemplo de esto es el rostro sufriente de Cristo en la cruz. La exigencia de la institución eclesiástica ante ese rostro es de que se le ha de contemplar viviendo en carne propia su dolor, por lo mismo cualquier conato de risa se hace acreedor al castigo. La risa es una transgresión contra la seriedad y el orden que en ella encuentra eco.

Pero si el segundo libro de la Pó́ica legitima la risa, por el prestigio que su autor goza en el medievo, entonces el orden establecido se tambalea, las certezas se obnubilan y el mundo va al garete sin la guía de lo sagrado; "no se puede reír de la verdad, so pena de abrir la brecha en ella" : tal es el argumento que Jorge de Burgos (trasunto de Jorge Luis Borges), el bibliotecario ciego, lanza contra sus perseguidores $\mathrm{G}$ uiller- 
mo de Baskerville, el monje detective, y Adso de Melk, su discípulo, parajustificar la destrucción del manuscrito aristotélico mientras sigue empeñado en su bibliofagia. La persecución se prolonga a través de las simetrías desconcertantes del laberinto bibliotecario. En él se confunde y repite vertiginosamente, sus pisos, salas y pasillos se bifurcan trastocando adelantey atrás, arriba y abajo. El laberinto bibliomorfo es testigo de la huida del Minotauro ciego, seguido de cerca por el fraile Teseo. Jorge de Burgos en cuya memoria está grabada la cartografía de subiblioteca con el fuego de la pasión y la nostalgia por los libros que alguna vez leyó con sus propios ojos, busca entre la tiniebla el pasillo que lo conduce ala sala "Y" deY SPANIA, reflejo bibliográfico en el laberinto de su tierra natal España. Es allí alcanzado por sus perseguidores y al sentir cerca la llama de la lámpara que sostiene Adso de Melk, se la arranca para lanzarla sobre los libros de la sala, que se convierten en una hoguera. A ella arroja los vestigios del manuscrito aristotélico que en el acto se hacen ceniza. El fuego cunde de una sala a otra, como invitación del papel a la inmolación: "Todo sucedió en pocos instantes: una llamarada se elevó desde los libros, como si aquellas páginas milenarias llevasen siglos esperando quemarse y gozaran al satisfacer de golpe una sed inmemorial de ecpirosis". ${ }^{1}$ Fuego que también consume el cuerpo del Minotauro bibliotecario. La lengua de fuego fatiga toda la extensión de la biblioteca, que es devorada en su totalidad. Laberinto ígneo: eco del laberinto en llamas de la biblioteca de Alejandríay de todas aquellas bibliotecas que han tenido ese destino. Ésteya famoso pasaje de la literatura del siglo XX es el momento culminante de la novela de Umberto Eco El nonbredelarosa.

En ese pasaje final de la novela se hacen plenamente evidentes aspectos que habían sido con anterioridad sólo una susurrante presencia como una alegoría del conflicto teológico entreel bien y el mal, el tejido semiótico que le da su textura y el complejo entramado de intertextualidades que le suministra densidad polifónica; sin embargo, a todo ello lo cubre la sombra omnisciente de la biblioteca, que de hecho es la presencia que les da unidad, coherencia y legibilidad. Presencia que en sí misma la convierte en uno de los personajes centrales, sino es que en el principal de El nom bredela rosa.

En la biblioteca no sólo se da la resolución final de la trama, sino que además su presencia cubre todo el desarrollo de la misma a tal grado quea semejanza de los personajes principales, Guillermo de Maskerville y Jorge de Burgos, va adquiriendo un perfil propio y autónomo a lo largo del desenvolvimiento de la novela; 0, más exactamente, los mencionados personajes asumen un relieve propio y diferencial desde el momento en que se recortan del trasfondo de la biblioteca. Esto encuentra explicación a partir de los signos que ambos encarnan: el signo de Jorge de Burgos es el del biblicteario, mientras que el de G uillermo de Baskerville es el del letor. Signos determinados por el código que dicta esa época histórica.

1 Umberto Eco, El nombredela rosa, Barcelona, RBA Editores, 1993, p. 45. 
La época que sirve de marco histórico a la novela es la del primer tercio del siglo X IV, pleno "otoño de la Edad Media". Es la dilatada fase de transición hacia el mundo moderno, lo cual sutilmente se refleja en la biblioteca de la abadía, aunque en ella aún predomine la estructura medieval de pura conservación, de pasividad y de sustancial clausura. La biblioteca de la novela sigue todavía el modelo bibliotecario del alto medievo (hasta antes del siglo X II) que consistía en una colección de libros más o menos ordenada antes que en una institución autónoma. Colección a la que se te nía como una parte del tesoro de la comunidad y que servía como complemento para el desarrollo de las funciones religiosas en la Iglesia anexa, a la vez que era un instrumento para la aculturación del personal eclesiástico alfabetizado y para el funcionamiento de la escuela anexa a la institución. Al mismo tiempo que este modelo medieval emite sus últimos destellos van surgiendo nuevos modelos de biblioteca acordes con las exigencias de la modernidad, como las de los colegios universitarios, las de las órdenes medicantes y las de los docentes laicos, que permitían un acceso amplio y libre a ellas. Jorge de Burgos define su signo como bibliotecario a partir de la estructura, del modelo de la biblioteca que él protegey a él protege. Su "visión" de la biblioteca es que debe ser templo y prisión que custodia la verdad inmutable, intangible y eterna. La suya es la demencial pasión por la estabilidad, que anhela detener el tiempo hasta el advenimiento del juicio final, sin que se añada nada a lo ya existente. Toda búsqueda ha de quedar proscrita, nada de novedades y cambios que puedan menoscabar la revelación. En cuanto bibliotecario que custodia la verdad revelada que mora en su biblioteca se considera a sí mismo un flamígero instrumento del castigo de D ios, que cae sobre todo aquel que no respete esa verdad o que pretenda transgredirla con la risa. A sí pues, la bibliotecale da relieve a Jorge de Burgos como personaje principal de la novela a partir de que se erige como una proyección y un preservador de su estructura medieval. La biblioteca dibuja la figura del bibliotecario.

Por su parte $\mathrm{G}$ uillermo de Baskerville es el inquisidor en el sentido dual del término: por haber sido miembro del Santo $O$ ficio y por ser el interrogador, esto es, el que pregunta y cuestiona, el lector de los signos del mundo. Para él no existe una verdad revelada que le dé orden inmutable al mundo y, como fiel discípulo de su correligionario franciscano Guillermo de 0 ckham, descree de la metafísica de Tomás de Aquino que observa que el conjunto de seres que pueblan el mundo obedecen a un orden intangible; por el contrario, estima que el poco de orden que existe lo proyectamos con nuestras opciones cognoscitivas gracias a la ayuda de los signos que nos ofrendan el mundo y los libros. Su mente inquisitiva, que acepta y se apasiona con el novedoso, concibe la lectura como un medio para el conocimiento de las leyes del mundo inmediato y de sus cambios. Conocimiento que no debe ser de clausura sino estar abierto para todos. Guillermo de Baskerville es ya un protohombre de la modernidad que hafrecuentado las nuevas bibliotecas que permiten el libreacceso a un mayor número de lectores. Por eso los contornos de su figura se delínean a partir de su oposición a la biblioteca abacial a la que le es negado el acceso, para satisfacer su hambre (soberbia, lujuria diría Jorge de Burgos) de saber y para seguir investigando 
los homicidios de los monjes. La biblioteca dibuja la figura del lector que excluye, aquél que se convierte en transgresor de su normatividad institucional.

Conforme se suceden las muertes de los monjes la presencia ominosa y sagrada de la biblioteca, llamada el Edificio, tórnase mayormente protagónica y compleja. Complejidad que incluso rebasa el marco histórico y ficcional de la propia novela para adentrarse en el territorio de lo imaginario. La biblioteca como estructura a través de la cual se transparenta la interacción de historia e imaginario. La biblioteca, además de ser un acontecimiento histórico, es un acontecerimaginario. Cada uno de los modelos bibliotecarios surgidos en la historia es el resultado de las condiciones específicas de cada contexto, por lo que llenan una serie de necesidades sociales que se encuentran imbricadas con procesos sociales imaginarios, los cuales se concretan en una serie de representaciones que sirven como guía para la construcción de cada modelo histórico. Todo modelo bibliotecario antes de realizarse en bibliotecas específicas y concretas es imaginado. El nombredelarosa, de manera explícita, exhibe la dimensión histórica de la biblioteca, pero nos remite fuera de este marco para hundirnos implícitamente en la dimensión del imaginario que produjo la representación de la biblioteca como laberinto.

El fuego que inicia Jorge de Burgos recorre la biblioteca propagándose con creciente voracidad a los pisos inferiores de la construcción que ocupan el saiptaiumy el refectorio. Sin exceso metafórico puede decirse que es el fuego del tiempo histórico el que calcina esos tres espacios que alberga el edificio. Incendio del tiempo que convierte en ceniza una ancestral historia bibliotecaria. Palabras atrás señalé que la biblioteca de la A badía se encontraba suspendida en un tiempo que ya no era el suyo sino el vestigio de una estructura y una práctica bibliotecaria que había cerrado su ciclo. En ella están aún vivas las características de las bibliotecas del alto medievo, a pesar de que se le ha infiltrado el rumor de los nuevos tiempos expresado, por ejemplo, en el incontenido deseo de saber, en la apetencia de novedades que contaminan el espíritu de aquellos monjes suicidas que leen el manuscrito de laPớica. Pero donde se evidencia de manera inmediatala referenciaal pasado de tal biblioteca es precisamente en la colindancia física que tiene con el scriptoriumy el refectorio dentro de la misma construcción, la cual está expresando en la simbología medieval la unidad de tres componentes del cuerpo humano: en la planta baja el refectorio simboliza las funciones digestivas, en el siguiente nivel el scriptoriumsimboliza el sistema circulatorio cuyo centro rector es el corazón y en el nivel superior la biblioteca, que simboliza la función intelectiva radicada en el cerebro.

Las bibliotecas anteriores al siglo X II al par de ser lugar de conservación y clausura de los libros, son el espacio de la escritura y la lecturaregamentadaen el momento de la oración y la comida que sellevabaa cabo en el refectorio. Lo más destacable de se mejante modelo es lainterrelación del sciptoriumy la biblioteca: que expresa la identidad entre escritura y lectura; empero, no son prácticas signadas por la creatividad sino determinadas por el principio de sumisión a la autoridad y a la tradición. Los copistas que trabajan en el sciptaiumleían el strictosensupara reproducir un texto, en la 
mayoría de los casos ya canonizado.La copia una vez terminada, con la ayuda del Se ñor, era atesorada en la biblioteca, que asimismo venía a ser su tumba. La piadosa misión del monje copistano incluía el estudio o la reflexión del texto reproducido, es más, por la salvación de su alma era algo que tenían terminantemente prohibido, como se lo explica el Abad Abbone a fray Guillermo de Baskerville: "Porque no todas las verdades son para todos los oídos, ni todas las mentiras pueden ser reconocidas como tales por cualquier alma piadosa, y, por último, los monjes están en el scip toriumpara realizar una tarea determinada, que requiere la lectura de ciertos libros y no de otros, y no para satisfacer la necia curiosidad que puedan sentir, ya sea por fla queza de sus mentes, por soberbia o por sugestión diabólica" .2 Por otra parte, es conjeturable que aunque no pesara sobre los copistas ese mandato superior, el mismo agobio que significaba la tarea de la escritura mimética no les dejaba demasiada energía y tiempo para la crítica o la creatividad. Sin diferenciarsemucho delos copistas, los intelectuales eclesiásticos responden también al principio de autoridad y continuidad: leen para componer un texto propio hecho en su mayor parte de citas ajenas. Leen escribiendo, por lo que pueblan continua, extensa y permanentemente los márgenes y las interlíneas con notas, es el ejercicio del arte de los marginaliallevado hasta su último extremo. Escriben al compás de la lectura o inmediatamente después de haber leído. El libro y el documento de hecho pertenecen a la misma esfera delaescritura. El documento representala crónica yla memoria dela comunidad religiosa. Así pues, los intelectuales eclesiásticos tampoco ejercen la escritura como una práctica creativa y crítica. No copiaban exclusivamente textos, pero sí componían libros que eran mero comentario, reflejo opaco de los textos estudiados en la biblioteca: el libro que escriben está de antemano condenado a quedar enterrado junto a los libros que comentan en la biblioteca, de ahí la inalienable continuidad de ésta con el scriptorium Lectura y escritura son prácticas sin fronteras divisorias, circularidad autárquica del vínculo entre los espacios de la biblioteca y el scriptorium

La tradición tiene una inextinguible fuerza de perseverancia que hace que sus esquirlas sobrevivan más allá de la época que la vio nacer. En el transcurso del siglo XII va dándose la desintegración del antiguo modelo bibliotecario como consecuencia del surgimiento de un nuevo modelo, el cual se consolida a lo largo del siglo XIII; empero, so breviven algunas antiguas bibliotecas como la deEl nombredelarosa. Ello en buena medida se debió a su situación geográfica del aislamiento que les sirve como precaria defensa contra los primeros aires de la modernidad. Es un periodo en el que inéditas formas de organización social se desarrollan y cuyo centro son las florecientes ciudades; en ellas crecen las escuelas universitarias.

Todo esto trae aparejada la formación de un amplio público de personas cultas o alfabetizadas que hicieron que el número de libros aumentara. Las bibliotecas universitarias así como las eclesiásticas ampliaron sus acervos y esto redundó en que tuvieran que modificar su estructura física para abrirse a una consulta más amplia. Asi-

2 Ibid p. 36. 
mismo entre las órdenes mendicantes nace el modelo de biblioteca religiosa de consulta, con libros encadenados a los bancos de lectura. Las transformaciones que ocurren en el horizonte histórico social repercuten de múltiples maneras en la integridad de la estructura bibliotecaria, incluso hasta en la traza física, arquitectónica de las bibliotecas. El diseño del espacio arquitectónico es reflejo de las estructuras mentales de cada sociedad y época históricay por lo mismo el diseño decualquier biblioteca es expresión de las necesidades y aspiraciones del contexto social. Los cambios que se producen en la estructura bibliotecaria no son automáticos ni homogéneos y en algunos casos se dan de manera parcial o con bastante retraso, como ejemplifica esto último la biblioteca que custodia Jorge de Burgos.

Las transformaciones que sufre la E dad Media en su caso conllevan la desarticulación de la mentalidad escolástica, lo que produce una serie de rupturas a todo lo largo del modelo de biblioteca alto medieval. La unidad entre libro y documento se rompe, lo que significa la disociación entre biblioteca y archivo. Un abismo se abre entre la unidad de lectura y escritura o, lo que es lo mismo, entre la biblioteca y el saiptrium A horala mayor parte de los libros ya no son copiados en el sciptoriumanexo a la biblioteca, sino que vienen del exterior porque son encargados, adquiridos o legados y hasta obtenidos de manera nonsanda como un botín, mediante saqueo o robo; como es el caso de todos los hermosos manuscritos del A poalipsisentre los que se encontraba la segunda parte de la Pótica, que trae a la biblioteca de la Abadía Jorge de Burgos como botín de su viajea León y Castilla. Botín que lo hizo famoso y estimado entre su comunidad y queademás le ayudó a obtener el puesto de bibliotecario. La ruptura del vínculo entre el espacio de escrituray el espacio de lectura se tradujo en que la biblioteca de jaba de ser en exclusiva un lugar de mera conservación y se transfiguraba también en un espacio de consulta y lectura; lo quevino a significar el privilegiamiento de lapráctica autónoma de la lectura. Mientras que la escritura quedó restringida a grupos específicos minoritarios a la vez que iba adquiriendo un nuevo cariz que ya no la supeditaba sólo a la copia o al comentario. La autonomía de le lectura conllevó el establecimiento de un nuevo modo de estudiar, de consultar los textos y memorizarlos, y también impuso la necesidad de usar simultáneamente un gran número de textosyyano de pocos en lenta sucesión. El manejo de varios libros implica cotejarlos enfrentando las visiones, los discursos, la ideas y las "verdades" en ellos contenidas, lo que termina dando como resultado laactitud crítica: base dela mentalidad moderna. Crítica que por necesidad conduce a la quiebra del principio de autoridad, con lo que el libro deja de ser un vehículo de continuidad de la tradición así como un receptáculo de la verdad trascendente. Situación a la que tanto temía el bibliotecario ciego. Visto al trasluz de esa situación histórica la Pớicao, más exactamente, la risa que el manuscrito destila, simboliza el espíritu de la crítica.

Todo esto nos reconduce directamente al problema medular de la biblioteca abacial que de hecho es el problema clave de todo ese modelo bibliotecario: la censura. Problema que es la cara oculta de la apertura y difusión del conocimiento que no hace esta biblioteca. D ifusión y censura son inseparables y necesarias para la estruc- 
tura bibliotecaria. Incluso las bibliotecas que se fundan en una completay democrática apertura de su acervo, del conocimiento, tienen muy afinados sus mecanismos de censura, pero en ellas actúan de manera más subrepticia; mientras que en bibliotecas como las de la novela esos mecanismos quedan totalmente al descubierto, al grado de que el bibliotecario se convierte de manera abierta en la representación de la censura, como lo ejemplifica sin lugar a dudas Jorge de Burgos. Mas el papel de censor que él asume no es sólo producto de las tortuosidades apocalípticas de su mente sino además el resultado de vivirse como caja de resonancia de su tiempo histórico. La censura en las bibliotecas no se deriva únicamente de las actitudes personales de sus bibliotecarios o de políticas bibliotecarias preestablecidas, de hecho éstas en buena medida son reflejo de las tendencias de diverso orden que configuran a las sociedades en cada época histórica.

Cada uno de los modelos bibliotecarios aparecidos a lo largo de la historia es producto de las condiciones específicas de cada contexto social y llena una serie de necesidades de diversa índole. Las instituciones creadas por un contexto histórico social específico son factor de cohesión de la colectividad, a la par de ser impulsoras de su proceso civilizatorio. Pero tales instituciones se encuentran signadas por la necesidad de continuidad y preservación, por lo que tienen que generar mecanismos de defensa contra todo aquello que pretenda desastibilizarlas, lo que se traduce en el terreno concreto en censura, coerción, control, exclusión...Así cada institución codifica los mecanismos de censura de acuerdo con sus propias características específicas y diferenciales siempre en consonancia con la necesidad de preservar el sistema social en el cual surgió y del cual es expresión. D e ahí quelainstitución bibliotecaria codifique sus mecanismos de censura de acuerdo con un modelo que responde a las necesidades del contexto histórico social, y que de manera efectiva se hace visible en las políticas bibliotecarias y en el accionar de los bibliotecarios: quienes como individuos concretos son finalmente hombres de su tiempo. Pero esto lleva a la pregunta ¿por qué bibliotecas como la de El nombredela rosa hacen explícita la censura?

El universo al que pertenece claramente la biblioteca abacial es el medievo, lo que significa un horizonte histórico social dominado por la religión, y en cuanto tal sus mecanismos de censura radican en el precepto religioso. Pero no cualquier religión sino exclusivamente la cristiana, cuyo ejercicio tiende a hacerla exclusiva. El cristianismo medieval se sustentaba sobre una institución eclesiástica cuyo dogmatismo no admitía la práctica de otras religiones, pero además ese mismo dogma tenía fundamento en una cosmovisión teológica dominada por la figura de D ios. A partir de esa figura se organiza jerárquicamente el mundo, cada objeto, ser, grupo social o individuo tienen en esajerarquía una posición predeterminada, inamovible y, en cuanto tal, son receptores de laverdad divina, que por lo mismo es inmutable e incuestionable. Y para hacer prevalecer esa verdad la Iglesia tiene instrumentos y mecanismos de represión y censura, el principal: la Inquisición. Esta instancia de represión viene a ser la corporización de la necesidad de autodefensa que el sistema social medieval genera para su propia sobrevivenciay continuidad, pero el al mismo tiempo tal corporización 
le manifiesta que no hay razón para ocultar su tendencia represoray censora porque, en última instancia, está avalada por la defensa de la verdad divina. La Inquisición es el espejo donde se reflejan y encuentran un modelo de codificación y los mecanismos de censura específicos y diferenciales de cada institución, así como cada uno de los principales y más preclaros miembros de esas instituciones se convierten en una proyección del inquisidor. Esto explica por quélaintegridad dela estructura delabiblioteca abacial está dominada de manera explícita por la censura (como vimos con las prácticas de la lectura y la escritura) y por qué su bibliotecario Jorge de Burgos cumple ceñidamente con la función de inquisidor bibliógrafo: que sabe muy bien que con su actividad censora contribuye a la sobrevivencia delaEdad Media. Lo curioso de esto es el trastocamiento de los roles porque mientras que el bibliotecario ciego representa al gran inquisidor, G uillermo de Baskerville, ex-inquisidor, defiende la libertad del saber.

La función censora del bibliotecario se justifica, pues, a partir de la defensa de la verdad divina que debe mantener herméticamente incontaminada, incluso, expurgándola de los libros escritos bajo el designio de la mentira, lo que a su vez acarrea la férrea protección y clausura del acervo de la biblioteca, como justifica el propio Abad: "Sólo el bibliotecario, además de saber, está autorizado a moverse por el laberinto de los libros, sólo el sabe dónde encontrarlos y dónde guardarlos, sólo él es responsable de la conservación:
(...) Los monstruos existen porque forman parte del plan divino, y hasta en las horribles facciones de los monstruos se revela el poder del Crea- dor. D el mismo modo, el plan divino contemplala existencia de los libros de los magos, las cábalas de los judíos, las fábulas de los poetas paganosy las mentiras de los infieles. Q uienes, durante siglos, han querido y soste- nido esta abadía estaban firme y santamente persuadidos de que incluso en los libros que contienen mentiras el lector sagaz puede percibir un pá lido resplandor de la sabiduría divina. Por eso, también hay esa clase de obras en la biblioteca. Pero como comprenderéis, precisamente por eso cualquiera no puede penetrar en ella. Además - añadió el Abad casi excu- sándose porla debilidad de este último argumento- , el libro es una criatu- rafrágil, se desgasta con el tiempo, teme alos roedores y sufre cuando cae en manos inexpertas. Si a lo largo de los siglos cualquiera hubiese podido tocar libremente nuestros códices, la mayoría de éstos ya no existirían. Por tanto, el bibliotecario los defiende no sólo de los hombres sino tam- bién de la naturaleza, y consagra su vida a esa guerra contra las fuerzas del olvido, que es enemigo de la verdad. ${ }^{3}$

Palabras, pues, que muestran cómo el Abad está en consonancia con la censura. Jorge de Burgos es el bibliotecario que a pesar de su ceguera, o precisamente gracias

3 Ibid p. 36-37. 
a ella, se mueve con levedad por el laberinto de los libros sabiendo dónde encontrarlos y dónde guardarlos, lo que lo autoriza a ejercer sin contemplaciones de ninguna índole la censura a lo largo de toda la estructura bibliotecaria, ${ }^{4}$ base de su poder dentro de la abadía, aún por encima del Abad. Al dominar la biblioteca, Jorge de Burgos, de hecho, domina la abadía. La biblioteca es el centro en torno al cual gira la vida de los monjes de la abadía benedictina. "Estaban dominados por la biblioteca, por sus promesas y sus interdicciones. Vivían con ella, por ellay, quizá, también contra ella, esperando, precisamente, poder arrancarle algún día todos sus secretos" ${ }^{5} \mathrm{Y}$ es precisamente a la comunidad de la abadía a la que de manera inmediata hay que proteger por medio dela censura contra las acechanzas de la malignidad del tiempo moderno, aun a costa de matar a los monjes más inquietos. Su celo de censor bibliógrafo lo conduce directamente al homicidio y a la bibliofagia.

En un diálogo iluminador que entablan Guillermo de Baskerville y su discípulo Adso de Melk se hace referencia a la red de relaciones que se dan entre los libros, lo que viene a conformar un unives dediscoursdentro del cual se muestra que los libros no son entidades que existan por sí mismos, sino que están entrelazados unos con otros pos diversos hilos. Asimismo en el diálogo que indica la función de la censura dentro de esa red de relaciones de libros cuyo territorio de contención es la biblioteca:

- ¿Cómo? ¿Para saber que dice un libro debéis leer otros? - A veces es así. Los libros suelen hablar de otros libros. A menudo un libro inofensivo es como una simiente, que al florecer dará un libro peligroso o viceversa, es el fruto dulce de una raíz amarga. - Es cierto - dijeadmirado. Hasta entonces había creído que todo libro hablaba de las cosas, humanas o divinas, que están fuera de los libros. De pronto comprendí que a menudo los libros hablan de libros, o sea que es casi como si hablasen entre sí. A la luz de esa reflexión, la biblioteca me pareció aún más inquietante. [...] - Pero entonces - dije- ¿de que sirve esconder los libros, si de los libros visibles podemos remontarnos a los ocultos? - Si se piensa en los siglos, no sirve de nada. Si se piensa en años y días, puede servir de algo. - ¿ ¿De modo que una biblioteca no es un instrumento para difundir la verdad, sino para retrasar su aparición?-preguntéestupefacto. - No siempre, ni necesariamente. En este caso sí. 6

4 Ramiro Lafuente en su libro Biblictecadigtal yordandbamental especifica las características centrales dela estructura bibliotecariaal definir la biblioteca como "[...]laidea de seleccionar, adquiriry organizar documentos, con laintención de ordenarlos bajo un sistema de clasificación que permita una organización metódica de sus contenidos, con objeto de fomentar el uso de los mismos en el seno de una comunidad. El análisis y sistematización de los contenidos temáticos de los documentos permiteformar un cuerpo unificado de conocimiento que facilita saber acerca de los documentos y los temas que tratan a través de descripciones sintéticas de la forma física, ubicación, y materias arboladas, así como sus relaciones de afinidad semántica con los tópicos de otros documentos".

5 Umberto Eco, qp at. p. 173.

6 Ibid, pp 270-271. 
Indudablemente Jorge de Burgos suscribiría estas opiniones, pero con la notable diferencia de que sus conclusiones serían diametralmente opuestas, así como las acciones que emprendería derivadas de ello.

El bibliotecario, a igual que Guillermo de Baskerville, es en el sentido pleno del término un hombre de libros (y no por el simple expediente de que Jorge sea bibliotecario, sabido es que esa no es conditiosinequanonpara el ejercicio de tal actividad), porque ambos han forjado su vida a través de la lectura de los libros, son lo que son gracias a ellos, por lo mismo, saben de la red de intertextualidades que se teje dentro del universo de los libros. Pero mientras G uillermo de Baskerville siguiendo ese tejido puede construir un liveimagnaire, como es la segunda parte de la Pótica, ${ }^{7}$ expandiendo con ello aún más el universo de intertextualidades, Jorge de Burgos, por su lado, sabe del peligro que representa para su comunidad y para su mundo medieval que ese tejido siga expandiéndose a partir del libro aristotélico. Existen libros que por su carga transgresora y renovadora se convierten en núcleos con base en los cuales se gesta la red de intertextualidades, y conformetal red se dilatava transfigurando la realidad histórica. El universo de los libros reconstituye el universo de lo real, que a su vez dibuja las sendas por las que aquél seguirá ampliándose. Pero Jorge de Burgos opta por cegar tales sendas: quiere detener la expansión del universo deintertextualidades abriendo en él un agujero negro con el ocultamiento del manuscrito aristotélico en lo más recóndito de la biblioteca laberinto, que es convertida así en instrumento para retrasar la aparición de la verdad, lo que asimismo implica seguir alimentando el hálito de vida que les queda a las instituciones del antiguo régimen.

Mas esa clausura de la verdad acaba por ser un incentivo para su búsqueda por lectores transgresores, como Guillermo de Baskerville. Como último recurso de censura contra un lector de semejante temple, Jorge deBurgos decide destruir el manuscrito. Pero el hecho consumado de que el bibliotecario llegara a la bibliofagia y a la ecpirosis indica su incapacidad personal, así como la del modelo bibliotecario que él representa, de defenderse contra los cambios que va imponiendo el surgiente mundo moderno. Cuando un sistema social cambia es porque las necesidades de la colectividad están cambiando con mayor premura. Unas instituciones sustituyen a otras. En el terreno bibliotecario esto significa que un modelo es sustituido por otro, lo cual es notorio para el modelo que encarna la biblioteca abacial cuyos días, por lo

7 Al decir que la segunda parte de laPótica es un liveimaginaireno significa total inexistencia, por el contrario, cabalmente existe aunque como constructo simbólico. Mas la condición de posibilidad para que sea un constructo simbólico es que existan antecedentes o vestigios de que sí fue o pudo ser escrito. D iógenes Laercio, compilador delas obras de Aristóteles, da noticia delos dos libros de la Pótica, aparte de que el propio estagirita no ahorro pistas y referencias de esa sección de su libro. El carácter simbólico de un libro imaginario estriba en que con contenido textual pasa a segundo término, para convertirse en símbolo de ideas o de una concepción del mundo. El poder del símbolo radica en su capacidad de construcción imaginaria de la realidad. La realidad social es un laberinto entramado de símbolos. 
mismo, están contados. Como un designio de ese destino final aquel que más quiso protegerla fue el instrumento flamígero elegido para consumirla.

\section{POST SCRIPTUM}

No es una mera ornamentación agregar algunas palabras sobre lo que puede considerarse el misterio mayor que envuelve a la biblioteca de El nombredelarosa: su arquitectura fantástica. La traza arquitectónica de cualquier construcción está en consonancia con las estructuras mentales de la sociedad y la época histórica en que es llevada a cabo; sin embargo, la biblioteca abacial no responde al diseño arquitectónico de las bibliotecas del alto medievo, a cuyo modelo histórico pertenece, que consistían en una habitación cerrada en la que sólo se atesoraba la ordenada colección de libros. Y mucho menos se parece al espacio arquitectónico de las bibliotecas del siglo X IV , que producen el diseño de la Iglesia de nave única, consistente en dos columnas sucesivas de bancos separadas por espacios laterales y centrales que facilitan el desplazamiento del público. Muy por el contrario, algo extraño sucede cuando se ingresa al espacio arquitectónico de la biblioteca abacial, tórnase completamente fantástica, como si emergiera de algún territorio onírico: es un espacio laberíntico. Así lo hace constar de sibilina forma el delirante y fallido bibliotecario Malaquías al ser interrogado al respecto por G uillermo de Baskerville: "— ¿La biblioteca es un la berinto? - La biblioteca es un gran laberinto, signo del laberinto que es el mundo. Cuando entras en ella no sabes si saldrás" . ${ }^{8}$ En la medida que la biblioteca le revela sus secretos a Guillermo de Baskerville su perfil se reafirma como un laberinto surcado de peligros, lo que gradualmente la va haciendo más irreal. Pareciera con ello que la dimensión histórica de la biblioteca fuera haciéndose difusa conforme se deja atrás el sciptonumpara adentrarse entre sus laberínticos meandros cubiertos de trampas. D e hecho puede decirse que esa zona de indefinición que media entre el saiptoriumy la biblioteca expresa la transición que en la novela conduce de lo histórico a lo fantástico. Transición que subrepticiamente murmura en las palabras de Ma laquías cuando pone de manifiesto que la biblioteca es un laberinto y, en cuanto tal, signo del mundo, el cual asimismo es un laberinto. En una variante tales palabras pueden interpretarse como que los libros son un laberinto de intertextualidades, que está contenido en el laberinto de la biblioteca, que a su vez está contenido en el laberinto del mundo: misenâbimedel laberinto. A hora bien, esa aura de irrealidad que rodea a la biblioteca por mediación de la representación del laberinto, nos dice de ma nera sigilosa que ella, en cierto modo, es más representativa que las bibliotecas concretas o más exactamente, que ella compendia algo esencial, común a todas las bibliotecas que han existido. En suma, puede decirse que la biblioteca laberinto dela

Ilid, pp. 149-150. 
novela viene a ser símbolo de los múltiples y distintos modelos bibliotecarios que han aparecido a lo largo de la historia.

Umberto Eco, teórico de la semiología, sabe bien de la necesidad, importancia y función de los símbolos, por lo que no es gratuita la elección que hace del símbolo del laberinto como representación de su biblioteca. ${ }^{9}$ Para él no es, pues, como pudiera creerse, un mero artilugio ficcional que le sirve como escenografía espectacular para darle densidad a la trama de su novela. Para Umberto Eco no hay duda de que el símbolo connatural no sólo de su biblioteca sino de la Biblioteca, en general, es el laberinto. Por sus propias características en el símbolo del laberinto está más potenciada la capacidad de ramificarse, de expandirse para representar la peculiar complejidad de ciertos territorios de la realidad. Por eso mismo es el símbolo idóneo para representar una entidad como la biblioteca, que es el ámbito de recepción, organización y expansión del conocimiento y lainformación quele sirveal ser humano para construir y transformar su realidad. Puede decirse entonces que el símbolo del laberinto como representación de labiblioteca es el que mejor expresa las características esenciales y definitorias de toda biblioteca. Laberinto de laberintos: la biblioteca, escorzo que complementa la dimensión histórica de la biblioteca que queda de manifiesto a lo largo dela novela. Historicidad y permanencia, cambio y continuidad son los extremos entre los que oscila el péndulo de la biblioteca, como parece decírnoslo Umberto Eco con esa maquinaria de relojería narrativa que es El nonbredela rosa.

\section{BIBLIOG RAFÍA}

Braunfels, Wolfgang, Arquiteturamonacal enOcidente, Barcelona, Barral, 1975.

Cavallo, G uglielmo y Chartier, Roger (dirección), Histaiadelalectura end mundo ocidental, Madrid, Taurus, 1998.

D uby, George, Laépoca delascatedrales Arteysoiedad, 980-1420, Madrid, Cátedra, 1995.

9 Aunque es de subrayare que su elección del símbolo del laberinto también estuvo determinada por la obra de Jorge Luis Borges, para el cual el laberinto es, posiblemente, el más importante leitmotiv de su narrativa. Incluso del propio Umberto Eco es el primero en reconocer en su AposillasaEl nombredelarosala deuda que tiene con el gran ficcionador sudamericano: "Todos me preguntan por qué mi Jorge (de Burgos) evoca, por el nombre a Borges, y por qué Borges es tan malvado. No lo se. Quería un ciego que custodiase una biblioteca (me parecía una buena idea narrativa), y biblioteca más ciega sólo puede dar Borges, también las deudas se pagan". Más allá de la inocencia que fingen las palabras de E co la intertextualidad en su novela no se reduce a ambos bibliotecarios ciegos, es de hecho en la concepción de la biblioteca laberinto donde se deja sentir de manera más completa la influencia de Borges. Inclusive de manera muy particular es el cuento de Borges Labiblidecade Babd el que le sirve a Umberto Eco como arquetipo para la forma de su biblioteca laberinto. 
Eco, Umberto, AposillasaEl nombre de la rosa, Barcelona, Lumen, 1985.

Eco, Umberto, Arteybdleza enla estética medieal, Barcelona Lumen, 1999.

- - -, El nombredela rosa, Barcelona, RBA Editores, 1993.

- - - , La estructura ausente Introdución ala Seniớica, Barcelona, Lumen, 1976.

Gilson, Étienne, LafilosofíaenlaEdadMeela. Desdeloscrígenespatrísticos hasta $\mathrm{A}$ findd sigoXIV, Madrid, G redos, 1999.

Lafuente, Ramiro, Biblicteca digtal yorden doamental, México, CUIBUNAM, 1999.

Le G off, Jacques, La ơilizacoón da œcidantemedieal, Barcelona, Paidós, 1999. 